\title{
ББК 83
}

\section{ПРИЕМЫ СЛОВЕСНОЙ ЖИВОПИСИ ЮРИЯ АННЕНКОВА (НА ПРИМЕРЕ ЛИТЕРАТУРНОГО ПОРТРЕТА «БОРИС ПАСТЕРНАК»)}

\section{М. В. Олюнина}

Аннотация. В работе представлен анализ способов создания словесного портрета в восполинаниях Ю. Анненкова "Борис Пастернак" с обоснованиел жанрово-стилевых особенностей рассматриваелого словесного изображения, что позволяет по-новому взглянуть на уже ставший хрестолатийныл образ писателя. Запечатлевая образ поэта и прозаика Б. Пастернака, живописеи творит и автопортрет, и потрет эпохи. Так, литературное наследие Юрия Анненкова оказывается второй портретной галереей, для которой художник вновь пишет близких ему, дорогих людей, оставшихся на его полотнах. Целью данной работы является попытка показать особенности словесного изображения в книге воспоминаний Ю. Анненкова "Дневник моих встреч. Цикл трагедий" на примере очерка "Борис Пастернак", обогатить образ писателя через призму восприятия его современника-художника. Настоящее исследование строится с использованиел сравнительно-исторического и историкофбункиионального летодов и опирается на работы совреленных литературоведов, занилающихся теорией и историей портрета в прозе.

Ключевые слова: словесный портрет, очерк, восполинания, литературный портрет, синтез жанров, Юрий Анненков, Борис Пастернак.

\section{TECHNIQUES OF YURI ANNENKOV'S VERBAL PAINTING (ON THE EXAMPLE OF THE LITERARY PORTRAIT "BORIS PASTERNAK")}

\section{V. Olyunina}

Abstract. The article analyzes the ways of creating a verbal portrait in the memoirs of Yu. Annenkov's „Boris Pasternak” with the substantiation of genre and style features of the considered verbal image which allows to take a fresh look at the already textbook image of the writer. Capturing the image of the poet and prose writer B. Pasternak, the painter creates both a self-portrait and the portrait of the era. Thus, Yuri Annenkov's literary heri- 
tage turns out to be the second portrait gallery, for which the artist once again paints his relatives and dear people, who remained on his canvases. The purpose of this work is an attempt to show the features of verbal image in Yuri Annenkov's book of memoirs "Diary of my meetings", "Cycle of tragedies" on the example of the essay "Boris Pasternak", to enrich the image of the writer through the prism of perception of his contemporary artist. This study is based on comparative historical and functional methods and is based on the works of contemporary literary scholars engaged in the theory and history of prose portrait.

Keywords: verbal portrait, feature article, memories, literary portrait, synthesis of genres, Yuri Annenkov, Boris Pasternak.

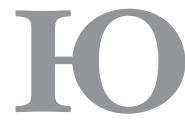

рий Анненков, который известен не только современникам, но и нашему поколению как выдающийся живописец, график, художник театра и кино, также является автором сборника «Дневники встреч. Цикл трагедий», который все чаще привлекает внимание филологов [см. 1-3]. Особая манера письма Анненкова, отражающая его бытность графика, совмещение в творчестве монтажных и коллажных структур, присущих кинематографу, делают его литературное наследие уникальным феноменом прошедшей эпохи. Портреты графические, созданные автором и предваряющие литературные портреты, иллюстрации и рисунки Юрия Анненкова, его литературное творчество, прежде недооцененное на родине, сегодня вызывает интерес у российской и франкоговорящей аудитории.

Что касается второго тома его литературной работы «Дневник моих встреч», нельзя не отметить его выраженную антисоветскую направленность. Если портреты из первой части книги («Максим Горький», «Анна Ахматова» и другие) наполнены лиризмом, тоской и светлыми воспоминаниями живописца, том второй представляет собой порой завуалированную, но чаще открытую критику строя, а потому многие образы современников Анненкова, вписанные в эпоху, оказываются видоизмененными в угоду намерениям автора. Так, коротенький очерк «Алексей Толстой» делает из упомянутого писателя личность скорее анекдотическую, нежели талантливую, а в исследуемом в данной статье очерке «Бо- рис Пастернак» большую часть занимают вырезки из газет той эпохи, показывающие чудовищность советского строя, рассуждения самого Юрия Анненкова об ошибочности выбранного властями пути.

Тем не менее нельзя отказать вышеупомянутому литературному портрету в живописной образности. Мы встретим в нем мало описаний внешности вынесенного в заголовок персонажа, однако метонимия, жанровые зарисовки и приемы коллажа и монтажа позволяют Юрию Анненкову создать самое важное - образ эпохи, а также Бориса Пастернака с его судьбой, вписанной в нее. Лейтмотивом очерка является мысль Анненкова о том, что главным в личности и творчестве Пастернака была его принадлежность к последним русским писателям и поэтам - сам живописец на протяжении всего очерка курсивом выделяет прилагательное «русский», особо отмечая, что «там» (в России) теперь осталась разве что Ахматова, и больше никого - если не считать подпольных авторов.

В паре с графическим портретом, открывающим очерк, мы можем найти аналогичный ему портрет словесный: «Борис Пастернак: огромные глаза, пухлые губы, взгляд горделивый и мечтательный, высокий рост, гармоничная походка, красивый и звучный голос. На улицах, не зная, кто он, прохожие, в особенности - женщины, инстинктивно оглядывались на него» [4, с. 152]. К слову, как в словесном, так и на графическом портретах особое внимание уделяется именно глазам и губам, выписанным художником с лаконичным мастерством, а 
также взгляду, для которого были выбраны эпитеты «мечтательный» и «горделивый». Пожалуй, здесь уместно вспомнить портрет Пастернака, который несколькими деталями рисует В. Катаев в повести «Алмазный мой венец»: его внешний облик (не зря Катаев скрывает своего друга под псевдонимом «мулат») наполнен жарким солнцем («еще более посмуглевший» [5, с. 184]), которое также является воплощением и признанного (пусть и с ноткой веселой иронии) Катаевым поэтического гения. Так, читаем: «...стоял [Пастернак. - М. О.] настолько выше как признанный гений, что мог считаться не только председателем нашей попойки, но самим богом поэзии, сошедшим в Мыльников переулок в обличии мулата с конскими глазами и наигранно простодушными повадками Моцарта, якобы сам того не знающим, что он бог» [5, с. 203]. Совершенно разные портреты, глаза уже - конские, манеры «наигранно простодушные», хотя сравнение с Моцартом, бесспорно, расширяет визуальную характеристику Бориса Пастернака.

Вообще, возвращаясь к живописцу, Анненкову удается передать внешнюю гармонию, которая является важнейшей составляющей облика Пастернака, что, на наш взгляд, становится показателем и гармонии внутренней, оказывающейся впоследствии выше нападок власти. Пастернак - красавец, который при этом объявляет себя застенчивым (анекдотический случай, когда поэт показал девушке, засмотревшейся на него, язык, обвинив в этом свою стеснительность), но при этом, как ловко замечает Анненков, подобное душевное качество не распространяется на творческое и гражданское мужество Пастернака.

В своем очерке Анненков противопоставляет себя Пастернаку: так, поэт живет в Москве, художник - в Петербурге, отмечает живописец и разницу их мастерства, однако «в эту эпоху мы все, вся артистическая молодежь России (и не только России), были воодушевлены одинаковым стремлением к искательству новых (часто противоречивших друг другу) форм художественного выраже- ния, и это - в самых разнообразных родах искусства: литература, живопись, музыка, театр...» [4, с. 152-153]. «Мы» - так объединяет себя и людей эпохи Анненков, показывая неразрывное единство творцов, стремящихся и ищущих, однако потом, словно грань между этими воодушевленными поисками, приходит революция.

Уходит эпоха, и вот уже те, кто не может отказаться от прошлого, оказываются вписаны, как и сам Пастернак, в ряды «попутчиков»: линия «мы» расходится, и теперь на словесном полотне Анненкова появляется новое единство, главной чертой которого живописец считает постепенное принятие коммунистической идеологии и постепенный же отказ от индивидуального понимания литературных задач. Появляется целый ряд имен - Зощенко, Иванов, Пильняк, которые связаны с новыми принципами творчества, но больше имен - Зайцев, Бунин, Мережковский и другие - тех, кто покинул родину, и автор не боится потратить на их перечисление целую страницу своего очерка. Кто-то вернется, чтобы «превратиться в сталинского придворного» («Алексей Толстой»), а кто-то - чтобы умереть (Куприн, Цветаева...), однако остается Пастернак, встретивший революцию, как и многие (и снова обобщенное «мы», в которое Анненков не стесняясь включает Блока, Есенина и Маяковского), скорее в облике стихийного порыва, метели, музыки. И пока попутчики постепенно становятся советскими писателями, Пастернак, по мнению Анненкова, остается на своей родине писателем русским, выражающим собственные чувства и мысли вопреки «дирижерской палочке», уходит не только от футуристов, веря, что поэзия не может служить, но от любых социальных лагерей вообще. Дается своеобразный, почти фотографический портрет: Пастернак и Ахматова, Пастернак и Цветаева, и др. И именно этот выбор пути оказывается наиболее трудным: Анненков называет Пастернака внутренним эмигрантом, и уже здесь звучит попытка объединить определенных творческих людей в одну среду, в которой оказался и сам Юрий Анненков. Те, кто хотя бы вну- 
тренне не покинул СССР, гибнут или кончают жизнь самоубийством, и только по счастливой случайности выживают такие, как Пастернак. Вообще, на протяжении всего литературного портрета слышится обида, которую испытывает живописец к своей родине. И есть на что обижаться: любимая дача в Куоккале была загублена революционерами, статус талантливого портретиста и иллюстратора потерял значимость.

Анненков много пишет про советское и русское искусство, упрекая первое в рабском подчинении, постоянно повторяя, что революция поработила искусство, лишила его свободы; автор много и нелестно отзывается о Хрущеве и других деятелях той эпохи, однако для нашего исследования политическая позиция живописца не оказывается важной. Впрочем, на наш взгляд, именно она мешает Юрия Анненкову здраво размышлять о плюсах и минусах романа «Доктор Живаго», в котором он видит противостояние гения диктаторской власти. Впрочем, сегодня история издания известна подробнее, и нет смысла делать из Пастернака мученика. Так, например, упоминания Анненкова о запрете публикаций Пастернака сейчас кажутся преувеличенными: однотомник поэта переиздается каждый год с 1933 по 1936, Пастернак много переводит (Шекспира, Гете), в 1943 г. выпускает сборник стихотворений «На ранних поездах», активно изучает творчество Николая Бараташвили, печатает о нем статьи. Анненков же признает героичность Пастернака, приводит ужасающие собранные в газетах вырезки и статьи с гневным обличением писателя. Во многом анализируемый очерк и задумывался как оправдание романа Бориса Пастернака и обличение той среды, в которой ему приходится сперва молчать, а затем страдать от гневных нападок. Анненков сравнивает вынужденное молчание Пастернака в течение многих лет с молчанием прекрасной Ахматовой - именно таким эпитетом сопровождает живописец поэта, а неподкупность, честность уже самого Пастернака, которые он проявит в романе «Доктор Живаго», по мнению Анненкова, и станут причиной негодования советской власти. Полагаем, именно из-за внутренней установки на обвинение властей и собственного трагического опыта заканчивает свой очерк Анненков не собственными словами и впечатлениями, лирической нотой, часто из собственных, сокровенных воспоминаний, но статьей Эренбурга о Пастернаке, которую не слишком аккуратно вплетает в нить своего повествования, обвиняя автора в социальном заказе на данную статью, а потому осуждая его за нападки на Пастернака, касающиеся его творческого и просто человеческого эгоизма. Однако стоит понимать, чем было вызвано подобное мнение, а потому для нас главным оказывается не политический контекст или субъективное политизированное мнение о творчестве Бориса Пастернака, а то лирическое, портретное, что живописец вкладывает в свой литературный портрет «Борис Пастернак». И мы находим не только прямое описание, о котором уже говорили выше.

Кроме того, важным в портретном описании является упоминание о том, что Пастернак, хотя и был москвичом, все же подлинной родиной мог назвать Вселенную и Вечность, «более близких границ он, при его дальнозоркости, не замечал» [4, с. 157]. Здесь же Анненков приводит значимую цитату самого Пастернака, в которой - автопортрет поэта: «В кашне, ладонью заслонясь,// Сквозь фортку крикну детворе:// Какое, милые, у нас// Тысячелетье на дворе?// Кто тропку к двери проторил,// К дыре, засыпанной крупой,// Пока я с Байроном курил,// Пока я пил с Эдгаром По?» [4, с. 157]. Это - голос самого Пастернака в коллажной структуре произведения Анненкова, пастернаковский автопортрет, тот контекст, в который живописец, вслед за самим поэтом, пытается вписать его: контекст общемировой, не ограниченный рамками советского творчества и мира вообще. Здесь же - воспоминания о размышлениях Пастернака об Италии, которую он считает родиной нашей архитектуры, и отзвук синтеза искусств, который был ведущим принципом творчества у ориентиров Анненкова, не зря он вспоминает: Пастернак часто повторял, что для 
него поэзия немыслима без музыки, при этом последняя является искусством ведущим. Пастернак, тонко чувствующий эту связь двух искусств, не делал при этом поэзию абстрактной и внепредметной, упоминая лишь смещение действительности, произошедшее благодаря производимому чувству, и в этом Анненков видит еще одну причину, по которой Пастернака не приняли в реалиях новой России. Однако это - все еще портрет, лирика.

Важным эпизодом повествования можно назвать упоминание о 1921 г.: именно в это время Пастернак позировал Анненкову в его петербуржской квартире. Живописец отмечает, как Пастернак, устремив взгляд в угол комнаты, превратился в неподвижную статую: «Я этого не любил. Я всегда предпочитал модель, свободную в движениях, чтобы схватывать наиболее характерные положения, повороты, взгляды. Я попросил Пастернака разговаривать со мной, пока я рисую. Он улыбнулся и ответил: - А не будет ли легче для вас, если я стану только о чем-нибудь упорно думать, а не разговаривать?» [4, с. 159-160]. Оба они засмеялись, и Пастернак вспомнил историю, как Лев Николаевич Толстой позировал его отцу, тоже художнику, и тот попросил его интенсивно думать, на что великий писатель ответил, что только этим всю жизнь и занимается.
И тут - парный зеркальный портрет, два художника, создающие портреты людей своего времени, своей эпохи, таких выразительных и таких не похожих. Графический портрет был размещен в сборнике Пастернака «Сестра моя - жизнь», изданном в 1922 г., и Анненков в круговороте жизни и молодости не уделил ему должное внимание, но уже в своем очерке, анализируя прошедшее, с легкой грустью отмечает, что гордится этим томиком, который свел двух творцов на долгую жизнь.

В последний раз Пастернак и Анненков встретились уже в Париже, в 1935 г., «в этот год, будучи уже в полной славе, Пастернак не имел еще ни седых волос, ни морщин. В продолжение его краткого пребывания во Франции мы много говорили о Париже, а не о советской революции. Политика попрежнему его не интересовала. Нелепый парадокс нашей эпохи: именно совершенная надполитичностъ Пастернака поставила его к концу его жизни в центре политического международного скандала» [4, с. 163]. И важно в этом отрывке не упоминание политической позиции писателя, но сама встреча, воспоминание о ней и тот портрет Пастернака - еще молодого, разве что с намеком на седину и скорбную складку у губ, который мог бы быть написан, не окажись встреча последней.

\section{СПИСОК ЛИТЕРАТУРЫ}

1. Минералова И. Г., Олюнина М. В. Приемы словесной живописи при создании портрета Анны Ахматовой в книге Юрия Анненкова «Дневник моих встреч. Цикл трагедий» // Художественная словесность: теория, методология исследования, история: колл. моногр. / под ред. И. Г. Минераловой, С. А. Васильева. М.: Литера, 2018. C. 234-245.

2. Радченко М. М. «Дневник моих встреч» Ю. П. Анненкова: проблема жанрового синтеза: дис. ... д-ра филол. наук: 10.01.01. М., 2017. 148 с.

3. Скоболев Д. А. Эстетическая рефлексия Ю. П. Анненкова: на материале художественных и публицистических произведений: дис. ... канд. филол. наук: 10.01.01. Воронеж, 2009. 210 c.

4. Анненков Ю. Дневник моих встреч. Цикл трагедий. В 2 т. Т. 1. М.: Художественная литература, 1991. 346 с.

5. Катаев В. Алмазный мой венец. М.: Вече, 2018. 480 с

6. Башкеева В. В. Портрет как проблема // Вестник БГУ. Сер.: Филология. Улан-Удэ, 2008. Вып. 10. С. 139-143. 
7. Дмитриевская Л. Н. Словесная живопись в русской прозе XIX - начале XX вв.: дис. ... Д-ра филол. наук: 10.01.01. М., 2013. 354 с.

8. Лотман Ю. М. Статьи по семиотике культуры и искусства. СПб.: Академ. проект, 2002.

9. Минералов Ю. И. Теория художественной словесности (поэтика и индивидуальность). М.: ВЛАДОС, 1999. 360 с.

10. Николаева Т. Ю. Литературное наследие русских художников второй половины XIX первой половины XX века: дис. ... канд. филол. наук: 10.01.01. М., 2015. 188 с.

11. Тарабукин Н. М. Портрет, как проблема стиля // Искусство портрета: сб. ст. М., 1928. C. $159-193$.

\section{REFERENCES}

1. Mineralova I. G., Olyunina M. V. Priemy slovesnoy zhivopisi pri sozdanii portreta Anny Akhmatovoy v knige Yuriya Annenkova "Dnevnik moikh vstrech. Tsikl tragediy". In: Mineralova I. G., Vasilyev S. A. (eds.) Khudozhestvennaya slovesnost: teoriya, metodologiya issledovaniya, istoriya: koll. monogr. Moscow: Litera, 2018. Pp. 234-245.

2. Radchenko M. M. "Dnevnik moikh vstrech" Yu. P. Annenkova: problema zhanrovogo sinteza. PhD dissertation (Philology). Moscow, 2017. 148 p.

3. Skobolev D. A. Esteticheskaya refleksiya Yu. P. Annenkova: na materiale khudozhestvennykh i publitsisticheskikh proizvedeniy. PhD dissertation (Philology). Voronezh, 2009. 210 p.

4. Annenkov Yu. Dnevnik moikh vstrech. Tsikl tragediy. In 2 vols. Vol. 1. Moscow: Khudozhestvennaya literatura, 1991. $346 \mathrm{p}$.

5. Kataev V. Almaznyy moy venets. Moscow: Veche, 2018. 480 p.

6. Bashkeeva V. V. Portret kak problema. Vestnik BGU. Ser.: Filologiya. Ulan-Ude, 2008, Iss. 10, pp. 139-143.

7. Dmitrievskaya L. N. Slovesnaya zhivopis v russkoy proze XIX - nachale XX vv. PhD dissertation (Philology). Moscow, 2013. 354 p.

8. Lotman Yu. M. Statyi po semiotike kultury i iskusstva. St. Petersburg: Akadem. proekt, 2002.

9. Mineralov Yu. I. Teoriya khudozhestvennoy slovesnosti (poetika i individualnost). Moscow: VLADOS, 1999. 360 p.

10. Nikolaeva T. Yu. Literaturnoe nasledie russkikh khudozhnikov vtoroy poloviny XIX pervoy poloviny XX veka. PhD dissertation (Philology). M., 2015. 188 p.

11. Tarabukin N. M. Portret kak problema stilya. In: Iskusstvo portreta. Coll. of art. Moscow, 1928. Pp. 159-193.

Олюнина Маргарита Владимировна, магистр филологических наук, аспирант кафедры русской литературы XX-XXI веков Института филологии, Московский педагогический государственный университет

\section{e-mail: margooljunina@mail.ru}

Olyunina Margarita V., Master's degree in Philology, Postgraduate student, Russian Literature of the XX-XXI centuries Department, Institute of Philology, Moscow Pedagogical State University e-mail: margooljunina@mail.ru 